\title{
Training Hungarian neonatal transport nurses in screening for retinopathy of prematurity with telemedicine
}

\author{
ZS SOMOGYVÁRI ${ }^{1,2 *}$, E MAKA $^{3}, \mathrm{~J}_{\text {NÉMETH }}^{3}$ and ZZ NAGY ${ }^{1,3}$ \\ ${ }^{1}$ Department of Family Care Methodology, Faculty of Health Sciences, Semmelweis University, Budapest, Hungary \\ ${ }^{2}$ Neonatal Emergency \& Transport Service of the Peter Cerny Foundation (NETS-PCA), Budapest, Hungary \\ ${ }^{3}$ Department of Ophthalmology, Faculty of Medicine, Semmelweis University, Budapest, Hungary
}

(Received: August 20, 2019; revised manuscript received: October 10, 2019; accepted: October 25, 2019)

\begin{abstract}
Purpose: Remote screening for retinopathy of prematurity by wide-field digital imaging and network telemedicine is increasingly used to prevent blindness without the unnecessary transport of infants. Our purpose was to train and license dedicated neonatal transport nurses to do this in Hungary. Materials and methods: We developed a complex, four-step curriculum in mobile retinotelemetry. Using a robust selection process, we invited eight transport nurses $\left(\mathrm{N}_{\mathrm{t}} \mathrm{NP} / \mathrm{R}_{\mathrm{t}} \mathrm{N}\right)$ to receive training during the 2008-2017 project. The curriculum started with the basics of ophthalmology. Using an artificial eye, it continued with the theory and practice of ophthalmologic exams. Then, supervised by an ophthalmologist, each nurse performed 50 video recordings of anaesthetized and non-anaesthetized infants. Results: After demonstrating their competence, five of the eight candidate nurses received a license for retinotelemetry. During their subsequent practice, they had to undergo case reviews half-yearly by a specialist and renew their license every 2-3 years. During the 2008-2016 period, we analysed 7,177 remote screenings from a training perspective. During January 1-August 31 in 2017 period, we analysed extra data from 795 remote screenings of 332 infants from specific prevention perspectives. Conclusions: With the cooperation of preexisting neonatal transport service and the ophthalmological reading centre of a university hospital, a mobile telemedicine screening network was successfully developed in Hungary. Our results demonstrate how retinotelemetry can support different levels of prevention medicine. The network should work effectively and efficiently with continuous professional development.
\end{abstract}

Keywords: retinopathy of prematurity, wide-field digital imaging, telemedicine ROP screening, dedicated neonatal interfacility transport system, continuous medical education

\section{INTRODUCTION}

Retinopathy of prematurity (ROP) is one of the most frequent causes of blindness in infants. Early screening to detect ROP requiring intervention is essential to avoid severe visual impairment. According to the Hungarian national guidelines, ROP screening is required for all infants with a birth weight of $\leq 1,500 \mathrm{~g}$ or a gestational age of $\leq 32$ weeks. It is also required for infants with a birth weight between 1,500 and $2,000 \mathrm{~g}$ or a gestational age of more than 32 weeks who had an unstable clinical course [1].

Standard screening for ROP is performed by ophthalmologists using indirect binocular ophthalmoscopy (IBO) in a neonatal intensive care unit (NICU). In contrast, the new telemedicine-based method is performed using wide-field digital imaging (WFDI), with or without remote interpretation of images. The methods and validity of WFDI have been accepted all over the world, including Hungary [1-3]. The use a web-based WFDI telemedicine system allows the bedside screening of premature infants inside their incubators without transportation to the ophthalmologic centre and saves the ROP specialist from going to the NICU.
The transport-based telemedicine ROP screening of premature infants in Central Hungary was initiated by the Peter Cerny Foundation for Curing Sick Babies, a nongovernmental organization that provides the Neonatal Emergency and Transport Service-Peter Cerny Foundation (NETS-PCA). Previously, the NETS-PCA had been transporting 150-200 premature infants yearly for primary ROP screening, for control examinations and, if required, for laser treatment. To reduce the unnecessary transportation of fragile premature infants, in 1994, the Peter Cerny Foundation, in cooperation with the 2nd Department of Ophthalmology and the Level III NICU of the 2nd Department of Pediatrics of Semmelweis University, developed the possibility of performing cryopexia operations within the NICU, where they were performed for 4 years. Returning to the original goal of reducing the number of unnecessary transports, in 2008, the Foundation organized the Premature Eye Rescue Program (PERP),

* Corresponding author: Zsolt Somogyvári, $\mathrm{MD}, \mathrm{PhD}, \mathrm{MSc}$; Department of Family Care Methodology, Faculty of Health Sciences, Semmelweis University, Vas utca 17, Budapest H-1088, Hungary; E-mail: somogyvari.zsolt@se-etk.hu

This is an open-access article distributed under the terms of the Creative Commons Attribution 4.0 International License, which permits unrestricted use, distribution, and reproduction in any medium, provided the original author and source are credited, a link to the CC License is provided, and changes - if any - are indicated. (SID_1) 
a project for onsite ROP laser operation, and in 2009 innovated a telemedicine system. It was done with cooperation between the Department of Ophthalmology of Semmelweis University, which provided the ophthalmologic expertise, and the Peter Cerny Foundation, which provided not only the neonatal transport logistics but also the whole infrastructure and operation facilities of the webbased WFDI telemedicine system. After installing the mobile WFDI system (RetCamShuttle, Clarity USA) in a multifunctional neonatal ambulance van in 2009, we developed the training to enable transport nurses to take bedside videos of premature eyes in NICUs.

Although solutions to the problem of training nonmedical staff to use a web-based bedside WFDI telemedicine system are known [4-9], there have not been any data collected on applying this knowledge specifically to a neonatal transport-based service.

\section{MATERIALS AND METHODS}

Selection of candidate nurses was based on personality traits, attitudes, voluntary will, theoretical readiness, sophistication of skills, and at least 10-15 years of professional experience in neonatology. These were evaluated by the project-leader neonatologist of the NETS-PCA and by the pediatric ophthalmologist responsible for ROP in the Department of Ophthalmology at Semmelweis University. In the initial phase, two volunteer neonatal transport nurse practitioners $\left(\mathrm{N}_{\mathrm{t}} \mathrm{NP}\right)$ were selected and trained for ROP screening. During the whole project (2008-2017), a total of eight transport nurses $\left(\mathrm{N}_{\mathrm{t}} \mathrm{NP} / \mathrm{R}_{\mathrm{t}} \mathrm{N}\right)$ were invited to be trained in the bedside non-invasive ROP screening method.

Our training in bedside non-medical retinotelemetry consisted of four steps:

\section{0: Initial phase of PERP (August 05, 2008-November 29, 2009)}

A: To provide practical opportunities for the NtNPs to assist in IBO, as well as laser treatment. The training was led by the ROP specialist ophthalmologist, who was taken by the neonatal ambulance van to county hospitals with tertiary care centres, and who performed the special ROP-IBO exams and laser interventions with assistance from the transport nurses.

B: Before $\mathrm{N}_{\mathrm{t}} \mathrm{NPs}$ assisted the ROP specialist with the teleophthalmologic ROP screening, they were trained in the relevant basic knowledge.

1: Introduction phase of PERP (November 30, 2009 and August 08, 2010)

A: In 2009, after the mobile WFDI system (RetCamShuttle, Clarity USA) was installed in the multifunction neonatal ambulance van, the ROP specialist and the $\mathrm{N}_{\mathrm{t}} \mathrm{NP}$ were driven to the location of the infants, and the specialist personally performed the exams in nearby NICUs with the WFDI system and the assistance of the $\mathrm{N}_{\mathrm{t}} \mathrm{NP}-\mathrm{PCA}$.
$\mathrm{B}$ : Concurrent with this practical experience, the first two $\mathrm{N}_{\mathrm{t}} \mathrm{NP}-\mathrm{PCA}$ nurses studied a theoretical curriculum, which belonged to five blocks:

- Basic scientific knowledge of ROP ophthalmology (anatomical, physiological, pathophysiological backgrounds, and signs and symptoms of ROP),

- Basic scientific knowledge of emergency transport of neonates focused on ROP (technic, hygienic, logistic, and patient safety backgrounds),

- Basic scientific knowledge of using the noninvasive bedside mobile WFDI system (painlessand-safe interventions, video recording, image selection/reduction, picture transportation, backing up files, and documentation),

- Capability for error-searching of system failures,

- Basic scientific knowledge of how they could communicate/interpret data for NICU staff and parents, without interfering with the patient rights, $\mathrm{C}$ : Theoretical and practical exams based on the five blocks of the curriculum. Knowledge was measured by 50 multiple-choice test questions. The practical skill was measured using an artificial eye developed for educational surveillance by Clarity USA.

\section{2: Familiarization and practice phase (August 08, 2010-October 18, 2010)}

A: $\mathrm{N}_{\mathrm{t}} \mathrm{NP}$-PCAs who passed the exams successfully took part in eye operations at the Department of Ophthalmology weekly. First, they took video recordings before and after the operations, not only of premature babies. Later, they practiced how to place an eyelid speculum safely, painlessly, and gingerly into the eyes of non-anaesthetized premature infants. After 50 successful measurements, controlled by the ROP specialists in the operating theatre, they were allowed to go into hospitals to study bedside examinations.

$\mathrm{B}$ : In this phase, the ophthalmologist and the $\mathrm{N}_{\mathrm{t}} \mathrm{NP}$ were driven in PCA vans to nearby NICUs, where the $\mathrm{N}_{\mathrm{t}} \mathrm{NP}-\mathrm{PCA}$ performed WFDIs, closely supervised by the ophthalmologist. After successfully completing 50 examinations, the nurses were at the end of their training. The ROP specialist of the PERP awarded them a license, with which they are allowed to carry out the non-invasive screening independently, on the basis of the strict PERP protocols (preparations, screening itself, selection, cutting and sending pictures, data processing, documentation, hygienic tasks and communications, etc.).

\section{3: Independent practice phase with continuous medical education (CME; October 19, 2010-August 31, 2017)}

A: The $\mathrm{N}_{\mathrm{t}} \mathrm{NP}$-PCAs took bedside videos and edited them to select the characteristic pictures. They were technically supported by the PCA-driver (with data entry, cleaning, etc.) in the nearby NICUs (within $20 \mathrm{~km}$ ) and peripheral hospitals $(20-250 \mathrm{~km})$. Ophthalmologist specialized in ROP in the Review/Reading Centre received pictures via the Internet, evaluated them online, and gave advice to the PCA telemedicine/teleophthalmological team about what to do with the premature infant in the 
near future. Alternatively, the ophthalmologist could use a PCA van to join the ROP at the infant's location to perform a laser operation. For any operation, WFDI was performed before and after intervention for documentation purposes. In addition, the $\mathrm{N}_{\mathrm{t}} \mathrm{NP}-\mathrm{PCAs}$, as potential supplementary staff, could support patient safety with their skilled observational ability in the perioperative period. Last but not least, in the case of warranted ROP, premature infants could be urgently transported to the Ophthalmological Centre by the PERP team for laser treatment within as little as an hour.

\section{4: The weekly routine of $R O P$ screening}

A: For this purpose, three Level-III NICUs of Semmelweis University had a dedicated day for first or repeated screenings. The neonatologist requested exams according to the guidelines mentioned previously. Moreover, the non-university NICUs could use a telephone to request a teleophthalmological consultation/second opinion, which would be provided the same day in warranted ROP cases. The images could be captured by five well-trained $\mathrm{N}_{\mathrm{t}} \mathrm{NP} / \mathrm{R}_{\mathrm{t}} \mathrm{Ns}$ who worked in NETS-PCA and transported and resuscitated term and preterm babies on other days. They uploaded selected images and data (gestational age, birth weight, age, place of the examination, diseases, etc.) of premature infants to the secure review station and called the expert pediatric ophthalmologist to grade them. The expert described the infant's status, set the date of the next exam, and indicated the treatment and its date and place. If photocoagulation was indicated, the expert called the neonatologist, or, alternatively, sent a report (by e-mail or fax) to the NICU within $24 \mathrm{hr}$. If it was possible, the child remained in the original NICU and the team travelled to perform the bedside laser therapy.

B: CME with different levels of competence:

- For $\mathrm{N}_{\mathrm{t}} \mathrm{NP}-\mathrm{PCAs}$ : Daily case analysis was led by an ROP specialist. The retinotelemetry license had to be renewed by passing a theoretical exam every $2-3$ years. This was fulfilled by all of the five transport nurses successfully in 2012 and in 2014.

- At the same time as the bedside image processing, hospital staff and parents could look at the picture of the retina and understand the alterations. Supplemented by some standardized parental education materials. This "outreach education" helped NICU staff and parents get accustomed to the results of the examination.

- Ophthalmologist and neonatologist were offered post-graduate courses, accredited by the University (called the "OFTEX system" in Hungary).

\section{RESULTS}

\section{Selection and training of staff for mobile teleophthalmology}

Five of the eight candidates passed the theoretical and practical exams successfully and gained entitlement to self-employment (2010: 2/8, 2012: 2/8, 2015:1/8). Two of the eight rejected the request automatically (2010:2/8) and one of the eight withdrew in the $2 / \mathrm{B}$ phase for her negative emotional reasons (2012: 1/8). The five who passed their theoretical and practical exams achieved $4.5( \pm 0.5)$ out of a possible 5 marks.

\section{Results for the different curriculum phases}

Knowledge was measured by a 50-question multiple-choice test. The average number of right answers was $43( \pm 4)$. The practical skill was measured using an artificial eye developed for educational surveillance by Clarity USA. All of the candidates perfectly met the practical requirements. Performance indicators of the education process are summarized in Table 1.

Remarks.

- For the Introduction Phase: Out of 628 examinations performed by the ROP specialist, with assistance from the $\mathrm{N}_{\mathrm{t}} \mathrm{NP}-\mathrm{PCA}, 144$ were performed in peripheral hospitals and 484 in nearby NICUs. Of 73 laser treatments, 21 were performed in peripheral (rural) hospitals (far than $20 \mathrm{~km}$ ) and 52 in nearby NICUs closer than $20 \mathrm{~km}$.

- For the 2/A Familiarization Phase: Every $\mathrm{N}_{\mathrm{t}} \mathrm{NP}$ took 50 retina videos of anaesthetized infants in the operation theatre and 50 in NICUs, supervised by the ROP specialist.

- For the 3/A Independent Practice Phase: Five $\mathrm{N}_{\mathrm{t}} \mathrm{NP} /$ $\mathrm{R}_{\mathrm{t}} \mathrm{N}$-PCAs worked unaccompanied in meeting the different challenges of the daily routine (listed in results of 2017 - see below).

\section{Indicators of the clinical performance}

(a) The PERP was based on successfully developed neonatal transport logistics and has worked as an everyday routine since 2008 . Bedside screening was performed 7,177 times, and laser ROP treatment 465 times at 33 different institutes (14 Budapest and 19 county hospitals, which represented about $3 / 4$ of Hungary) between 2008 and 2016. Figure 1 shows the map of Hungary with the radius of the PERP.

(b) For certain tasks of prevention, we analysed data from the PERP between January 1 and August 31 of 2017. These data demonstrated that the WFDI telemedicine system can support different levels of prevention medicine. In this specific group, a total of 795 exams (690 in Budapest within $20 \mathrm{~km}$ and 105 at county hospitals $20 \mathrm{~km}$ further away) were performed on 332 premature infants, including 26 cases (17 in Budapest and 9 in counties) with laser treatments, with 215 van trips (181 times in Budapest and 34 times in the counties) totaling a distance of $8,253 \mathrm{~km}$.

For primary prevention in the ROP subgroup, of the 690 bedside examinations (in 10 hospitals of Budapest), the first screening of premature infants according to the Hungarian ROP guidelines was performed 412 times in three Level-III NICUs of Semmelweis University, and another Level-II NICU in a referral hospital of Budapest. For secondary prevention in the ROP subgroup, special medical second opinions were given in Budapest 251 times. For tertiary 
Table 1. Number of bedside examinations from the educational aspect (2008-2016)

\begin{tabular}{|c|c|c|c|}
\hline $\begin{array}{l}\text { Phases of Premature Eye Rescue } \\
\text { Program (PERP) }\end{array}$ & $\begin{array}{l}\text { Number of } \\
\text { examinations }\end{array}$ & $\begin{array}{l}\text { Number of } \\
\text { operations }\end{array}$ & Comments \\
\hline 0: Initial phase & 46 & 21 & IBO made by ROP specialist assisted by the first two $\mathrm{N}_{\mathrm{t}} \mathrm{NP}-\mathrm{PCA}$ \\
\hline 1: Introduction phase & 628 & 73 & WFDI made by ROP specialist assisted by the first two $\mathrm{N}_{\mathrm{t}} \mathrm{NP}-\mathrm{PCA}$ \\
\hline 2: Familiarization phase & $50+50$ & - & $\begin{array}{l}\text { WFDI made by } \mathrm{N}_{\mathrm{t}} \mathrm{NP} / \mathrm{R}_{\mathrm{t}} \mathrm{N}-\mathrm{PCA} \text { and controlled by ROP specialist } \\
\text { in the operation theatre }+ \text { in NICUs }\end{array}$ \\
\hline 3: Independent practice phase & 6,712 & $465^{*}$ & WFDI made by five $\mathrm{N}_{t} \mathrm{NP} / \mathrm{R}_{\mathrm{t}} \mathrm{N}-\mathrm{PCA}$ \\
\hline
\end{tabular}

Note. WFDI: wide-field digital imaging; IBO: indirect binocular ophthalmoscopy; ROP: Retinopathy of prematurity; NICU: neonatal intensive care unit; PCA: Peter Cerny Foundation; NtNP: neonatal transport nurse; NtNP/RtN: neonatal transport nurse practitioners/ registered neonatal transport nurse practitioners.

*Before and after laser treatments.

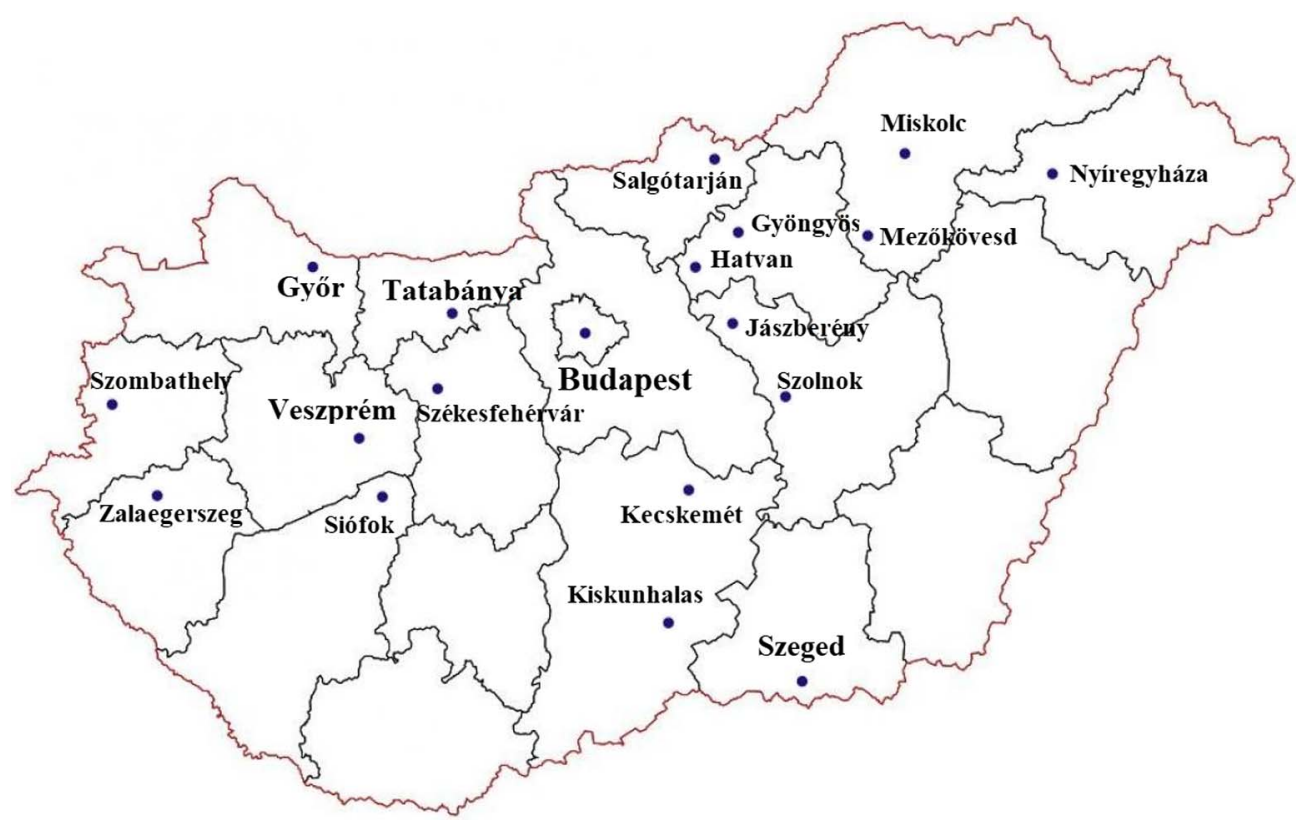

Figure 1. Places of teleophthalmological activity of PERP in Hungary (2008-2017)

prevention in the blindness subgroup, $27 / 17$ before-andafter imaging exams were performed for 17 laser coagulations based on teleophthalmology.

For the 39 bedside examinations in 8 county hospitals (20-230 km away), there was not any first screening because it was performed by the local ophthalmologist. Medical second opinions were given 92 times via telemedicine, and there were 13/9 before-and-after videos created for documentation purposes during the nine bedside laser treatments by the ROP specialist of the PERP.

In addition, during the summer holidays of the pediatric ophthalmologists, the PERP offered help with bedside WFDI screening to three hospitals in Hungary (20-230 km away), but there was no need for primary screening at that time.

\section{DISCUSSION}

Traditional ROP screening examinations with IBO must be performed by experts, and logistical difficulties may arise. As the number of premature babies grows, it is harder to find ophthalmologists who can manage the whole ROP prevention processes. According to expert opinion, more telemedicine programs will soon be available worldwide. In time, these programs should effectively combine the capture of retinal images, the possibilities of new telemedical technology, and the care of high-risk children. Telemedical ROP screening with RetCam wide-angle cameras (WFDI) is a safe and effective way to diagnose ROP in time for effective treatment. RetCam telemedical screening also provides objective documentation compared to drawings and descriptions after the IBO [7].

Teleophthalmological networks have been organized in many countries (USA, Canada, Bavaria, Poland, India, etc.) in the past decade [4-6]. These networks have many WFDI stationer unit cameras installed at Level-III NICUs and virtually connected with Reading/Review Centres. To create such a network with a stationer unit at every tertiary care location is expensive, but the yearly running cost is made cheaper with the use of a county-centralized reading centre $[6,10]$. Teleophthalmology is a good solution and the trend shows an increasing spread of this technology. In one survey, however, $55 \%$ of NICU directors stated they were neutral on whether or not it is safe to use telemedicine to screen for ROP [11].

The Mobil RetCam Unit (RetCamShuttle) was originally developed primarily for intrahospital/clinical (with short 
distance) usage. However, it could also be used for covering a greater geographical area with many hospitals, which lack an expert ROP workforce [6, 12].

Mobile ROP telemedicine facilities installed in a dedicated neonatal interfacility transport system comprise a unique solution for regularization and centralization of ROP screening and treatment. This solution is not only acceptable but also reduces the need for interhospital transfers [13] and the cost of middle- and long-term regional/national development [14, 15].

Building up a new teleophthalmological system and getting accustomed to evaluating two-dimensional pictures instead of three-dimensional pictures may be a difficult challenge for some ophthalmologists. Remote ROP diagnosticians should have the same training requirements as their bedside colleagues and a mentored experience in interpretation of digital images for ROP [2, 3]. Our ROP PERP specialist did not have any problem with this in the Introduction phase. There is no question that the non-medical telemedicine staff can liaise with the ROP specialist, who can decide whether the infant needs to be reexamined or needs a bedside laser treatment with or without transport. An online connection with the ophthalmologist at any time has ensured the safety of the teleophthalmological system similar to that of the PERP.

The other challenge is to educate non-medical staff who can perform the bedside non-invasive image capture, to select and to cut relevant pictures from the video independently, and to provide wider competencies for NICU nurses [3, 6, 7]. The transport NNP/RN combines an educational background with clinical experience and the flexibility to operate with an expanded scope of practice. Relative to clinic/hospital ophthalmological assistants, transport nurses offer more extensive clinical assessment skills, pharmacology experience, and critical care for complex disease processes. Additional procedural skills are institution-dependent but may include training on advanced airways, safety monitoring of vital functions, peripherally inserted central catheter placement, umbilical catheter placement, and the operation of specific advanced therapies in unexpected emergency situations.

Because of this expanded skill set and heightened familiarity with the logistics in different hospitals, our transport nurses, like visiting nurses [10], may be able to become a retinotelemetrist more easily than the unit-based nurses in Central Hungary. Besides their competencies enhanced with mobile retinotelemetry, transport nurses have been helping Hungary meet its prevention requirements:

- Primary prevention: To look for retinopathy in premature infants. The first screening of ROP in three Level-III NICUs of a University and one Level-II NICU in a Budapest Town Hospital based on the Hungarian ROP-Screening Directive (see above).

- Secondary prevention: To observe and prevent the progression of ROP with repeated/follow-up consultation or second opinions for many referral hospital ophthalmologists in Budapest and County Hospitals Levels II-III NICUs.

- Tertiary prevention: To prevent complications with photocoagulation (laser operations) as far as possible and avoid the risk of unnecessary transport of premature infants covering about 2/3 of Hungary.
- Particular task: Because of the tremendous lack of ROP specialists in Hungary, the PERP has been able to substitute some hospital ophthalmologists during summer holidays for the continuity of ROP screening, which may persist occasionally.

Expanding the competence of transport nurses for mobile retinotelemetry required a good candidate selection process and a complex curriculum. Our selection based on personality traits and experience among the PCA candidates for doing retinotelemetry was successful, proven by the fact that five of them have been practicing continuously for 7-7-5-5-2 years, and only one transport nurse gave up during the learning period because of emotional reasons. She was frustrated by an unpleasant feeling during the manipulation of premature eyes.

Key elements to our success were the gradual progress of the trainees and a consistent method:

- In the Initial phase, by assisting ophthalmologists who performed the IBO before laser treatment, transport nurses were socialized for this new challenge and approach.

- In the Introduction phase, when WFDIs were made by the ophthalmologist, nurses got considerable theoretical (explaining videos by the ROP specialist) and practical experience directly from the ophthalmologist. The second generation of the trainees could get a similar experience from their first-generation colleagues (the so-called "training the trainers" method).

- In the Familiarization phase, the 50-50 the transport nurses were safely supervised while taking retinotelemetry measurements on anaesthetized infants in an operation theatre.

- There is no doubt that the huge number of screenings in the Independent practice phase ensured the success of the project.

- The step-by-step build-up of the trainees with the training-the-trainers method was continued in the Independent practice phase, further increasing the effectiveness of the applied CME (see 3/B phase) and success of the project.

Indicators of clinical performance (see itemized PERP data of 2017) demonstrate that training non-medical and non-ophthalmologic staff for teleophthalmology using a well-designed curriculum and with the close, online cooperation, and leadership of ROP specialists could provide a reliable workforce for:

- Primary ROP screening of premature infants in NICUs;

- Primary screening of the whole at-risk population in NICUs;

- Repeated ROP screening/consultations/follow-up/ second medical opinions in hospitals;

- Repeated ROP screening/consultations/follow-up/ second medical opinions, in any places;

- Bedside laser treatment with retinotelemetry control in any hospitals with pediatric anaesthesiology facilities;

- Complicated operations in ROP centres with retinotelemetry control;

- Avoiding transport of premature infants in all cases (except the last one). 
Incremental benefits of the PERP as an "off label" transport activity are:

- For neonatology: stress and transport-related complications are avoided.

- For ophthalmology: time is saved, recordable images for follow-up and storage are made, and second opinions and international cooperation without traveling are made possible.

- For transport logistics: variability of team configuration is improved, and (based on multifunction vans) money is saved, and unnecessary transport is avoided.

- For all participants: e-documentation, quality assurance, interdisciplinary cooperation, and continuous education are made possible.

- Flexible utilization of preexisting transport facilities and human resources can efficiently support the telemedicine ROP screening.

- It is advantageous from economic aspects and returns on investment.

\section{CONCLUSIONS}

Using teleophthalmology for ROP screening and treatment of premature infants is a possible solution for the lack of ROP specialists. The number of telemedicine-based networks has increased worldwide over the past decade. The availability of mobile ROP screening based on the infrastructure of a dedicated neonatal interfacility transport system, and led medically by ROP experts, can improve ROP prevention, optimize the screening capacity of a limited workforce, and improve access to care. To organizing a mobile WFDI telemedicine system, it is essential to develop a well-designed curriculum for the training of transport neonatal nurses to take bedside pictures. Indicators of clinical performance demonstrate that training nonmedical and non-ophthalmologic staff for teleophthalmology with continuous step-by-step training and supervision could solve many of the problems in ROP prevention.

Acknowledgements: The authors would like to acknowledge to neonatal transport nurses Ildiko Jakab, Teodora Toldi, Eva Harangozo, Noemi Virag, and Maria Kacsandi who achieved extended competence to become "retinotelemetrists" and for their participation in the program.

Authors' contribution: ZsS involved in conception (neonatology and transport logistic and management) of telemedicine, acquisition, analysis, and interpretation, manuscript drafting, and editing. EM involved in conception (ophthalmology) of teleophthalmology, acquisition, and analysis and interpretation of data. JN and ZZN contributed in interpretation of data for the work, critical revision of the manuscript.

Ethical approval: The study is in accordance with the Declaration of Helsinki and all applicable local and international standards.
Conflicts of Interest/Funding: The authors declare no conflict of interest and no financial support was received for this study.

\section{ABBREVIATIONS}

$\begin{array}{ll}\text { ROP } & : \text { retinopathy of prematurity } \\ \text { IBO } & : \text { indirect binocular ophthalmoscopy } \\ \text { NICU } & : \text { neonatal intensive care unit } \\ \text { WFDI } & : \text { wide-field digital imaging } \\ \text { NETS-PCA } & : \text { Neonatal Emergency and Transport } \\ & \text { Service - Peter Cerny Ambulance } \\ \text { PERP } & : \text { Premature Eye Rescue Program } \\ \mathrm{N}_{\mathrm{t}} \mathrm{NP} & : \text { neonatal transport nurse practitioners } \\ \mathrm{N}_{\mathrm{t} P} \mathrm{~N} / \mathrm{R}_{\mathrm{t}} \mathrm{N} & : \text { neonatal transport nurse practitioners/ } \\ & \text { registered neonatal transport nurse } \\ \mathrm{CME} & : \text { continuous medical education }\end{array}$

\section{REFERENCES}

1. Integrált Jogvédelmi Szolgálat. Egészségügyi szakmai irányelv - A koraszülöttek retinopathiájának szüréséről, diagnosztikájáról, kezeléséről és szemészeti gondozásáról [Clinical practice guideline - guideline for screening, diagnostic, treatment and ophthalmic care of retinopathy of prematurity] [Internet]. Budapest: Hungarian Ministry of Human Capacities [Emberi Erőforrások Minisztérium]; 2016 [cited 2019 August 10]. Available from: http://www.obdk.hu/ ervenyes-egeszsegugyi-szakmai-iranyelvek.html [Hungarian]

2. Fierson, WM, American Academy of Pediatrics Section on Ophthalmology, American Academy of Ophthalmology, American Association for Pediatric Ophthalmology and Strabismus, American Association of Certified Orthoptists. Screening examination of premature infants for retinopathy of prematurity. Pediatrics. 2013;131(1):189-95.

3. Fierson, WM, Capone, A Jr, American Academy of Pediatrics Section on Ophthalmology; American Academy of Ophthalmology, American Association of Certified Orthoptists. Telemedicine for evaluation of retinopathy of prematurity. Pediatrics. 2015;135(1):e238-54.

4. Lorenz, B, Spasovska, K, Elflein, H, Schneider, N. Wide-field digital imaging based telemedicine for screening for acute retinopathy of prematurity (ROP). Six-year results of a multicenter filed study. Graefes Arch Clin Exp Ophthalmol. 2009;247(9):1251-62.

5. Fijalkowski, N, Zheng, LL, Henderson, MT, Wallenstein, MB, Leng, T, Moshfeghi, DM. Stanford University Network for Diagnosis of Retinopathy of Prematurity (SUNDROP): four-years of screening with telemedicine. Curr Eye Res. 2013;38(2):283-91.

6. Vinekar, A, Gilbert, C, Dogra, M, et al. The KIDROP model of combining strategies for providing retinopathy of prematurity screening in underserved areas in India using wide-field imaging, tele-medicine, non-physician graders and smart phone reporting. Indian J Ophthalmol. 2014;62(1):41-9.

7. Chiang, MF, Wang, L, Busuioc, M, et al. Telemedical retinopathy of prematurity diagnosis. Accuracy, reliability, and image quality. Arch Ophthalmol. 2007;125(11):1531-8. 
8. Raufi, NN, Morris, CK, Freedman, SF, Wallace, DK, Prakalapakorn, SG. Facilitated versus self-guided training of non-ophthalmologists for grading pre-plus and plus disease using fundus images for retinopathy of prematurity screening. J Pediatr Ophthalmol Strabismus. 2016;53(3):179-85.

9. Karp, KA, Baumritter, A, Pearson, DJ, et al. Training retinal imagers for retinopathy of prematurity (ROP) screening. J AAPOS. 2016;20(3):214-9.

10. Kemper, AR, Wallace, DK, Quinn, GE. Systematic review of digital imaging screening strategies for retinopathy of prematurity. Pediatrics. 2008;122(4):825-30.

11. Vartanian, RJ, Besirli, CG, Barks, JD, Andrews, CA, Musch, DC. Trends in the screening and treatment of retinopathy of prematurity. Pediatrics. 2017;139(1):pii:e20161978.
12. Moshfeghi, DM. ROP Screening Using Telemedicine [Internet]. Wayne, PA: Retina Today, Bryn Mawr Communications LLC; 2010 [cited 2019 August 10]. Available from: http:// retinatoday.com/2010/03/rop-screening-using-telemedicine/

13. Isaac, M, Isaranuwatchai, W, Tehrani, N. Cost analysis of remote telemedicine screening for retinopathhy of prematurity. Can J Ophthalmol. 2018;53(2):162-7.

14. Kovacs, G, Somogyvari, Zs, Maka, E, Nagyjanosi, L. Bedside ROP screening and telemedicine interpretation integrated to a neonatal transport system: Economic aspects and return on investment analysis. Early Hum Dev. 2017;106-7:1-5.

15. Chee, R, Patel, SN, Jonas, KE, et al. Current trends in telemedicine for retinopathy of prematurity. Vis Pan-Am Pan-Am J Ophthalmol. 2017; 16(1):7-11. 